\title{
Effect of chloride and sulfate ions on the advanced photo Fenton and modified photo Fenton degradation process of Alizarin Red S
}

\author{
L. Gomathi Devi*, C. Munikrishnappa, B. Nagaraj, K. Eraiah Rajashekhar \\ Department of Post Graduate Studies in Chemistry, Bangalore University, Central College City Campus, Dr. B. R. Ambedkar Street, Bangalore 560001, India
}

\section{A R T I C L E I N F O}

\section{Article history:}

Received 17 August 2012

Received in revised form 15 February 2013

Accepted 20 March 2013

Available online $\mathrm{xxx}$

\section{Keywords:}

Zero valent metallic iron powder

Alizarin Red S

Advance Fenton process

Combined ionic effect

Modified Fenton process

\begin{abstract}
A B S T R A C T
The degradation of Alizarin Red S (ARS) was carried out by heterogeneous advanced photo Fenton processes (HAPFP) of the type $\mathrm{Fe}^{0} / \mathrm{H}_{2} \mathrm{O}_{2} / \mathrm{UV}$ and heterogeneous modified photo Fenton process (HMPFP) of the type $\mathrm{Fe}^{0} / \mathrm{ammonium}$ persulfate (APS)/UV. The influence of various reaction parameters like $\mathrm{pH}$, catalyst loading, concentration of the oxidants and the influence of inorganic anions such as Chloride $\left(\mathrm{Cl}^{-}\right)$ and Sulfate $\left(\mathrm{SO}_{4}{ }^{2-}\right)$ ions on processes were investigated. Quenching of the hydroxyl radical by inorganic anions was confirmed by the decrease in the degradation rate constant for the HAPFP from $3.33 \times 10^{-2}$ to $0.19 \times 10^{-2}$ (for $\mathrm{Cl}^{-}(1 \mathrm{M})$ ) and $0.29 \times 10^{-2} \mathrm{~min}^{-1}$ (for $\mathrm{SO}_{4}{ }^{2-}(1 \mathrm{M})$ ). Similar decrease in rate constant for HMPFP is from $4.67 \times 10^{-2}$ to $0.41 \times 10^{-2}$ (for $\mathrm{Cl}^{-}(1 \mathrm{M})$ ) and $0.51 \times 10^{-2} \mathrm{~min}^{-1}$ (for $\mathrm{SO}_{4}{ }^{2-}(1 \mathrm{M})$ ) process. The combined effect of concentration of sulfate and chloride ions on the rate constant for the degradation of ARS with APS and $\mathrm{H}_{2} \mathrm{O}_{2}$ as oxidants is investigated. The initial degradation mechanism involves the cleavage of a quinone group to catechol as detected by UV-visible and GC-MS analysis.
\end{abstract}

(C) 2013 Elsevier B.V. All rights reserved.

\section{Introduction}

Anthroquinone dyes represent the most important class of commercial dyes. Alizarin Red S (ARS) belongs to the class of Anthroquinone dyes. Pollution of water by these dyes is a serious problem and the removal of these dyes from wastewater is a challenge to the related industries. Such stable compounds are difficult to destroy by common treatment methods because of its ability to chelate with specific cations. For the treatment of dye containing wastewater, advanced oxidation process (AOPs) is generally accepted as potential technique to treat organic pollutant in the industrial waste water. AOPs involve the generation of hydroxyl radicals in situ which is a powerful oxidant and can effectively mineralize almost all the recalcitrant compounds. The most common AOP techniques include photodecomposition of hydrogen peroxide $\left(\mathrm{H}_{2} \mathrm{O}_{2} / \mathrm{UV}\right)$, photolysis of Ozone $\left(\mathrm{O}_{3} / \mathrm{UV}\right)$, photocatalysis (semiconductor/UV), Fenton and photo Fenton's reactions $\left(\mathrm{Fe}^{2+} / \mathrm{H}_{2} \mathrm{O}_{2} / \mathrm{UV}\right)$ [1-4]. Compared to all the oxidation processes, Fenton's process (both homogenous and heterogeneous) is relatively economic and simple. The disadvantages of this methodology are sludge generation due to iron, slow regeneration of $\mathrm{Fe}^{2+}$ ions in the solution and also non reusability of the catalyst limits the efficiency of the reaction especially in homogenous process [5]. Iron and its oxides are widely explored in the degradation of the pollutants by hydroxyl

\footnotetext{
* Corresponding author. Tel.: +9108022961336.

E-mail address: gomatidevi_naik@yahoo.co.in (L.G. Devi).
}

radical generation [6-9]. Lucking et al. tested iron powder, graphite and activated carbon as active catalysts for the oxidation of 4chloropenol in the presence of $\mathrm{H}_{2} \mathrm{O}_{2}$ [10]. They concluded that metallic iron powder can replace iron salts as a catalyst in the photo Fenton process. The reduction of iron ions (from $\mathrm{Fe}^{3+}$ to $\mathrm{Fe}^{2+}$ ) on the iron surface proceeds at a faster rate in the heterogeneous process compared to the same reaction in the homogeneous process.

$2 \mathrm{Fe}^{3+}+\mathrm{Fe}^{0} \rightarrow 3 \mathrm{Fe}^{2+}$

The advantage of using solid metallic Iron powder is that it can be easily removed through filtration or centrifugation after the treatment. Contamination of Iron after the treatment is minimized. Whereas in the case of classical Fenton process $\mathrm{Fe}^{2+}$ ions are used as the catalyst and removal of these ions from the effluent is difficult task. Hence it is more advantageous to use $\mathrm{Fe}^{0}$ metallic powder as the catalyst from the environmental point of view. Moreover, use of $\mathrm{Fe}^{0}$ as catalyst instead of solution of iron salts prevents the additional anion loading in the treatment of waste water. The remaining iron powder can be easily removed and recycled after the treatment. The main aim of the present research work is to use Zero valent metallic iron (ZVMI) of 300 mesh size as a source to generate $\mathrm{Fe}^{2+}$ ions in the photo Fenton process. Industrial effluents are usually contaminated with various inorganic ions. The influence of these ions on the degradation rate is studied in detail. Individual and combined effects of $\mathrm{Cl}^{-}$(Chloride) and $\mathrm{SO}_{4}{ }^{2-}$ (sulfate) ions on the degradation rates were investigated in detail. Effect of inorganic anions on the photo degradation of ARS was studied. The effluents containing dyes are very difficult to treat because they contain 
various other ingredients like detergents, oils, inorganic salts etc. The present research work mainly aims at studying the influence of inorganic anions like Chloride $\left(\mathrm{Cl}^{-}\right)$and Sulfate $\left(\mathrm{SO}_{4}{ }^{2-}\right)$ on the heterogeneous advanced photo Fenton processes (HAPFP) of the type $\mathrm{Fe}^{0} / \mathrm{H}_{2} \mathrm{O}_{2} / \mathrm{UV}$ and Heterogeneous Modified Photo Fenton Process (HMPFP) of the type $\mathrm{Fe}^{0} / \mathrm{ammonium}$ persulfate (APS)/UV on the degradation rate.

\section{Materials and methods}

\subsection{Materials}

Alizarin Red S (ARS), iron powder (300 mesh size, electrolytic), ammonium per sulfate $\left(\left(\mathrm{NH}_{4}\right)_{2} \mathrm{~S}_{2} \mathrm{O}_{8}\right.$ (APS), and hydrogen peroxide $\mathrm{H}_{2} \mathrm{O}_{2}(\mathrm{HP})(50 \% \mathrm{w} / \mathrm{v})$, sodium chloride $(\mathrm{NaCl})$, sodium sulfate $\left(\mathrm{Na}_{2} \mathrm{SO}_{4}\right)$ were supplied from S D Fine Chemicals, Bombay, India and were used as received. The molecular formula, formula weight and $\lambda_{\max }$ of ARS are $\mathrm{C}_{14} \mathrm{H}_{6} \mathrm{Na}_{2} \mathrm{O}_{7} \mathrm{~S} \mathrm{H}_{2} \mathrm{O}, 360.28$ and $514-520 \mathrm{~nm}$ respectively.

\subsection{Irradiation procedure}

Advanced photo Fenton experiments were carried out at room temperature using a circular glass reactor whose surface area is $176.6 \mathrm{~cm}^{2} .125 \mathrm{~W}$ medium pressure mercury vapor lamp is used as the light source. Photon flux was found to be $7.92 \mathrm{~mW} / \mathrm{cm}^{2}$ by ferrioxalate actinometry $[11,12]$. The irradiation was carried out by direct focusing the light into the reaction mixture in open air condition at a distance of $29 \mathrm{~cm}$. The reaction mixture was continuously stirred. All the experiments were performed using double distilled water. The $\mathrm{pH}$ of the solution was adjusted either by adding dilute $\mathrm{NaOH}$ or dilute $\mathrm{H}_{2} \mathrm{SO}_{4}$ and it is measured by using Systronics Digital pH meter.

\subsection{Analytical methods}

The samples collected at different time intervals were centrifuged and filtered through $0.45 \mu \mathrm{m}$ Millipore filter to remove the catalyst particles. The centrifugates were analyzed by UV-visible and GC-MS spectroscopic techniques using Schimadzu UV-1700 Pharmaspec spectrophotometer and GC-MS-QP 5000 Schimadzu mass spectrometer. GC-MS analysis (using GC-MS-QP-5000 Shimadzu) and Thermo Electron Trace GC ultra coupled to a DSQ mass spectrometer equipped with an Alltech ECONO-CAP-EC-5 capillary column ( $30 \mathrm{~m} \times 0.25 \mathrm{mmi}$.d. $\times 0.25 \mathrm{~mm}$ film thickness) was used. Pure helium was used as the carrier gas at a flow rate of $1.2 \mathrm{ml} / \mathrm{min}$. The injector/transfer line/trap temperature was at $220 / 250 / 200^{\circ} \mathrm{C}$ respectively. Electron impact ionization was carried out at $70 \mathrm{eV}$. GC-MS-QP 5000 Schimatzu mass spectrometer was used to identify the intermediates formed during the degradation process.

\section{Results and discussions}

The various possible reactions taking place on the $\mathrm{Fe}^{0}$ surface with the oxidants are illustrated as follows:

Under acidic conditions iron powder undergoes oxidation to give ferrous ions $\left(\mathrm{Fe}^{2+}\right)$.

$\mathrm{Fe}^{0} \stackrel{\mathrm{H}^{+}}{\longrightarrow} \mathrm{Fe}^{2+}$

Iron powder in the presence of $\mathrm{H}_{2} \mathrm{O}_{2}$ generates $\mathrm{Fe}^{2+}$ ions which are partially adsorbed on iron surface. Further, these surface adsorbed $\mathrm{Fe}^{2+}$ ions can react with $\mathrm{H}_{2} \mathrm{O}_{2}$ leading to the generation of hydroxyl radicals.

$\mathrm{Fe}^{0}+\mathrm{H}_{2} \mathrm{O}_{2} \rightarrow \mathrm{Fe}^{2+}$-surface $+2 \mathrm{OH}^{-}$
$\mathrm{Fe}^{0}$-surface $+\mathrm{H}_{2} \mathrm{O}_{2} \longrightarrow \mathrm{Fe}^{3+}+2 \mathrm{OH}^{-}$

Alternatively iron powder can also react with oxidants like $\mathrm{H}_{2} \mathrm{O}_{2}$ and APS leading to the generation of $\mathrm{Fe}^{2+}$ ions in the bulk of the solution.

$\mathrm{Fe}^{0}+\mathrm{H}_{2} \mathrm{O}_{2} \rightarrow \mathrm{Fe}^{2+}+2 \mathrm{OH}^{-}$

$\mathrm{Fe}^{0}+\mathrm{S}_{2} \mathrm{O}_{8}{ }^{2-} \rightarrow 2 \mathrm{SO}_{4}{ }^{2-}+\mathrm{Fe}^{2+}$

These $\mathrm{Fe}^{2+}$ ions so formed can react with oxidants leading to the generation of active free radicals. During this process $\mathrm{Fe}^{2+}$ is oxidized to $\mathrm{Fe}^{3+}$.

$\mathrm{Fe}^{2+}+\mathrm{H}_{2} \mathrm{O}_{2} \rightarrow \mathrm{Fe}^{3+}+2^{\bullet} \mathrm{OH}$

$\mathrm{Fe}^{2+}+\mathrm{S}_{2} \mathrm{O}_{8}{ }^{2-} \rightarrow \mathrm{Fe}^{3+}+\mathrm{SO}_{4}{ }^{2-}+\mathrm{SO}_{4}$

Ferric ions $\left(\mathrm{Fe}^{3+}\right)$ so formed can either react with water or with $\mathrm{H}_{2} \mathrm{O}_{2}$ in the following two ways:

i) Ferric ions $\left(\mathrm{Fe}^{3+}\right)$ can react with water molecules to form aqua complex, which on UV-irradiation generates $\mathrm{Fe}^{2+}$ ions and hydroxyl radicals.

$\mathrm{Fe}^{3+}+\mathrm{H}_{2} \mathrm{O} \Leftrightarrow\left[\mathrm{Fe}(\mathrm{OH})^{2+}\right]+\mathrm{H}^{+}$

$\left[\mathrm{Fe}(\mathrm{OH})^{2+}\right]+h v \rightarrow \mathrm{Fe}^{2+}+{ }^{\bullet} \mathrm{OH}$

ii) Alternatively $\mathrm{Fe}^{3+}$ ions can also react with $\mathrm{H}_{2} \mathrm{O}_{2}$ leading to the generation of $\mathrm{Fe}^{2+}$ ions and hydroperoxyl radicals. This hydroperoxyl radical has the ability to reduce $\mathrm{Fe}^{3+}$ ions and simultaneously generate hydroxyl radicals. $\mathrm{Fe}^{2+}$ ions thus formed in the reaction can actively participate in the cyclic Fenton reactions as described by all the above equations.

$\mathrm{Fe}^{3+}+\mathrm{H}_{2} \mathrm{O}_{2} \rightarrow \mathrm{Fe}^{2+}+{ }^{\circ} \mathrm{O}_{2} \mathrm{H}+\mathrm{H}^{+}$

$\mathrm{Fe}^{3+}+{ }^{\circ} \mathrm{O}_{2} \mathrm{H} \rightarrow \mathrm{Fe}^{2+}+{ }^{\circ} \mathrm{OH}$

$\mathrm{Fe}^{3+}$ ions can also react with persulfate anion. Two molecules of sulfate radicals are produced which can react with water molecule leading to the generation of hydroxyl radicals.

$\mathrm{Fe}^{3+}+\mathrm{S}_{2} \mathrm{O}_{8}{ }^{2-} \rightarrow \mathrm{Fe}^{2+}+2 \mathrm{SO}_{4}^{-}$

$\mathrm{SO}_{4}{ }^{-\bullet}+\mathrm{H}_{2} \mathrm{O} \rightarrow \mathrm{SO}_{4}{ }^{2-}+{ }^{\bullet} \mathrm{OH}+\mathrm{H}^{+}$

\subsection{Effect of $p H$}

Kang et al. had reported that the pollutants can be decolorized efficiently in photo Fenton's process only under acidic conditions [13].

In the present study the experimentally observed degradation rate constants at $\mathrm{pH} 3$ are found to be $3.33 \times 10^{-2}$ and $4.67 \times 10^{-2} \mathrm{~min}^{-1}$ with $\mathrm{H}_{2} \mathrm{O}_{2}$ and APS as oxidants respectively (Fig. 1). At $\mathrm{pH} \mathrm{3}$, the concentration of $\mathrm{Fe}^{3+}$ ions and $\mathrm{Fe}[\mathrm{OH}]^{2+}$ complexes are the dominating photo active species which exist in almost equal proportions. The decrease in this optimum pH leads to decrease in the concentration of $\mathrm{Fe}[\mathrm{OH}]^{2+}$ complexes and it can also result in the precipitation of ferrous ions as oxy hydroxides. The various photoactive species of iron formed at different $\mathrm{pH}$ conditions are: $\mathrm{Fe}\left[\mathrm{H}_{2} \mathrm{O}\right]_{6}{ }^{3+}(\mathrm{pH} 1-2)$, Fe $[\mathrm{OH}]\left[\mathrm{H}_{2} \mathrm{O}_{5}{ }^{2+}(\mathrm{pH} 2-3)\right.$ and Fe $[\mathrm{OH}]_{2}\left[\mathrm{H}_{2} \mathrm{O}\right]_{4}{ }^{+}$(pH 3-4) $[14,15]$. The lower rate constant at $\mathrm{pH}$ 1.5 is mainly due to the excess $\mathrm{H}^{+}$ions in the solution acting as hydroxyl radical scavenger [16] (Eq. (15)).

$\mathrm{H}^{+}+{ }^{\bullet} \mathrm{OH}+\mathrm{e}^{-} \rightarrow \mathrm{H}_{2} \mathrm{O}$

Feng et al. had reported that the degradation efficiency decreases beyond the optimum $\mathrm{pH}$ conditions $(\mathrm{pH} 3)$ [17]. Dye 


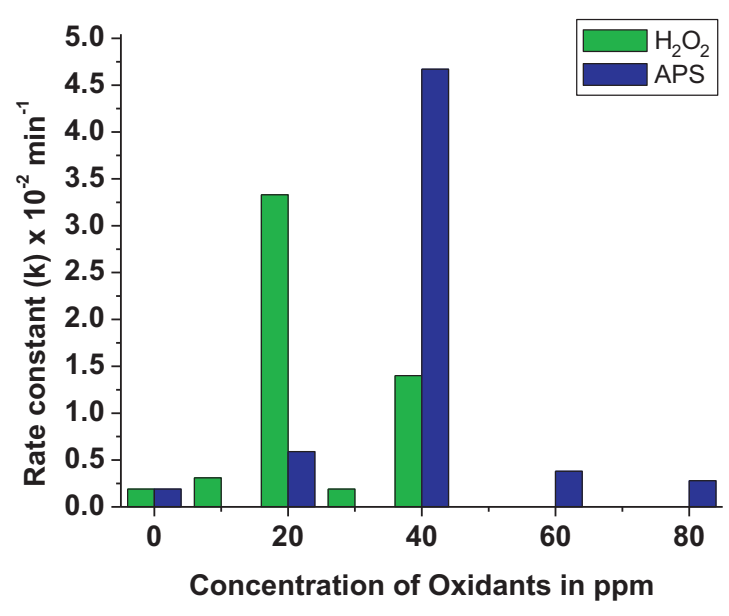

Fig. 1. Plot of rate constant versus concentration of oxidants $\left(\mathrm{H}_{2} \mathrm{O}_{2}\right.$ and APS) for the experimental conditions of: $\left[\mathrm{Fe}^{0}\right]=10 \mathrm{mg},[\mathrm{ARS}]=40 \mathrm{ppm}$ at $\mathrm{pH} 3.0 \pm 0.04$. The rate constants were calculated from the slope of the linear plot of $\log C / C_{0}$ versus time, where $C_{0}$ and $C$ are the initial and residual concentration of ARS at different time intervals.

resists degradation when the solution $\mathrm{pH}$ is greater than 7 . This is due to the coagulation of $\mathrm{Fe}^{3+}$ complex molecules in the reaction medium which inhibits the catalytic reaction of $\mathrm{Fe}^{2+}$ ions with the oxidants. At high $\mathrm{pH}$ conditions, iron oxy hydroxide precipitates and gets deposited on the surface of iron powder preventing the electron transfer between the catalyst and the oxidant. This hinders the process of formation of the hydroxyl radicals. Therefore both HAPFP and HMPFP experiments were carried out at optimized condition of $\mathrm{pH} 3$.

\subsection{Effect of oxidants}

The present study investigates the application of $\mathrm{H}_{2} \mathrm{O}_{2}$ and APS which are symmetrical peroxides and can be potential oxidants in the light induced reaction processes. Persulfate ions can generate sulfate and hydroxyl free radicals and they can provide free radical mechanism similar to hydroxyl radical pathways as generated in the Fenton's chemistry. Sulfate radical is one of the strongest oxidizing species in aqueous media with a redox potential of $2.6 \mathrm{~V}$, which is next only to the hydroxyl free radical whose redox potential is $2.8 \mathrm{~V}$. The sulfate radical anions produced in the case of APS shows various possible reaction mechanism in the process of mineralization which are as follows: (i) abstraction of hydrogen atom from the saturated carbon, (ii) The ions are capable of adding to the unsaturated compounds, (iii) It can remove an electron from the anions and neutral molecules [18,19]. These attributes combine to make the persulfate ions a viable option for the chemical oxidation of a broad range of contaminants. The influence of oxidants on the degradation rate was investigated by maintaining the other reaction parameters constant (Iron powder dosage $=10 \mathrm{mg}$, dye concentration $=40 \mathrm{ppm}$ at $\mathrm{pH} 3.0 \pm 0.04$ ). When the concentration of $\mathrm{H}_{2} \mathrm{O}_{2}$ was $20 \mathrm{ppm}$, the rate constant for the degradation is $3.33 \times 10^{-2} \mathrm{~min}^{-1}$ as shown in Fig. 1 . This is the maximum rate observed for $\mathrm{H}_{2} \mathrm{O}_{2}$. Higher or lower concentration of $\mathrm{H}_{2} \mathrm{O}_{2}$ decreases the rate constant. This can be due to the recombination of excessively generated hydroxyl radicals or these hydroxyl radicals may get involved in the unwanted reaction pathways as shown below:

$\mathrm{O}_{2} \mathrm{H}^{\bullet}+\mathrm{OH}^{\bullet} \rightarrow \mathrm{H}_{2} \mathrm{O}+\mathrm{O}_{2}$

$2 \mathrm{OH}^{\bullet} \rightarrow \mathrm{H}_{2} \mathrm{O}_{2}$
Table 1

Percentage degradation, rate constant and process efficiency values for the degradation of ARS at different experimental conditions.

\begin{tabular}{|c|c|c|c|}
\hline $\begin{array}{l}\text { Oxidation } \\
\text { processes }\end{array}$ & $\begin{array}{l}\text { Percentage } \\
\text { degradation }\end{array}$ & $\begin{array}{l}\text { Rate constant } \\
(k) \times 10^{-2}\left(\mathrm{~min}^{-1}\right)\end{array}$ & $\begin{array}{l}\text { Process efficiency }(\Phi) \\
\left(\times 10^{-12} \mathrm{ppm} \mathrm{Einstien}^{-1}\right)\end{array}$ \\
\hline $\mathrm{UV} / \mathrm{H}_{2} \mathrm{O}_{2}$ & 15 & 0.08 & 12.61 \\
\hline UV/APS & 26 & 0.14 & 18.83 \\
\hline $\mathrm{Fe}^{0} /$ dark & 18 & 0.01 & $14.27^{\mathrm{a}}$ \\
\hline $\mathrm{Fe}^{0} / \mathrm{H}_{2} \mathrm{O}_{2} /$ dark & 26 & 0.18 & $14.14^{\mathrm{a}}$ \\
\hline $\mathrm{Fe}^{0} / \mathrm{APS} /$ dark & 38 & 0.21 & $15.59^{a}$ \\
\hline $\mathrm{Fe}^{0} / \mathrm{UV}$ & 37 & 0.27 & 16.42 \\
\hline HAPFP & 74 & 3.33 & 52.41 \\
\hline HMPFP & 100 & 4.67 & 70.12 \\
\hline
\end{tabular}

a Process efficiency in dark process is expressed in ppm.

Similar experiments were carried out with APS and its optimum concentration was found to be $40 \mathrm{ppm}$ with a rate constant of $4.67 \times 10^{-2} \mathrm{~min}^{-1}$ (Fig. 1). The rate constant values calculated for the HMPFP is almost 1.5 times higher than HAPFP (Fig. 1). This is because of the influence of oxidants on the final $\mathrm{pH}$ of the reaction

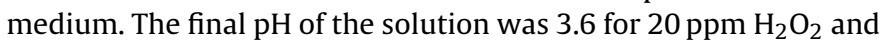
2.9 for $40 \mathrm{ppm}$ APS. Since APS provides better acidic $\mathrm{pH}$ condition which is most essential for the photo Fenton's process, it accelerates the rate of the reaction compared to $\mathrm{H}_{2} \mathrm{O}_{2}$. This favorable acidity conditions results in the higher concentration of the $\mathrm{Fe}^{2+}$ ions in the bulk of the solution due to the dissolution of iron powder. This further enhances the generation of hydroxyl free radicals. The $\mathrm{pH}$ of the solution was 2.12 after one hour of UV irradiation for higher concentration of APS ( $80 \mathrm{ppm})$. Hence rate constant drastically decreases to $0.68 \times 10^{-2} \mathrm{~min}^{-1}$. The excess acidity increases the concentration of protons in the solution which acts as hydroxyl radical scavenger. The observed higher $\mathrm{pH}$ in the case of $\mathrm{H}_{2} \mathrm{O}_{2}$ reduces the concentration of photo active species leading to the decrease in the rate constant.

\subsection{Effect of catalyst loading}

The optimization of the catalyst concentration is a necessary step in the photo Fenton reaction mechanism. The degradation efficiency in the absence of $\mathrm{Fe}^{0}$ catalyst was found to be 15 and 26 percent for $\mathrm{H}_{2} \mathrm{O}_{2} / \mathrm{UV}$ and APS/UV process for two hours of irradiation (Table 1 ) respectively. This is due to the direct photolysis of oxidants in the presence of UV light. However complete degradation and higher efficiency was achieved by the use of iron surface in the presence of oxidants. The iron surface catalytically decomposes the oxidants to respective free radicals/ions at a faster rate to generate more hydroxyl radicals under UV light. In contrast, overloading of the catalyst hinders the degradation efficiency. This may be due to: (i) higher concentration of the catalyst results in turbidity which hinders the UV light penetration [20]. (ii) Higher dosage of iron powder increases the concentration of $\mathrm{Fe}^{2+}$ ions in the solution which can also act as hydroxyl radical scavenger [16].

$\mathrm{Fe}^{2+}+\mathrm{OH}^{\bullet} \rightarrow \mathrm{Fe}^{3+}+\mathrm{HO}^{-}$

Additionally photo reduction of $\mathrm{Fe}^{3+}$ to $\mathrm{Fe}^{2+}$ ions takes place at a faster rate on the iron surface in HAPFP as shown by the following equation:

$2 \mathrm{Fe}^{3+}+\mathrm{Fe}^{0} \rightarrow 3 \mathrm{Fe}^{2+}$-surface

The increase in the dosage of iron powder shifts the reaction $\mathrm{pH}$ from acidic to alkaline condition which decreases the degradation rate. The shift in the $\mathrm{pH}$ mainly depends on the nature of the oxidants which can be explained as follows: When the catalyst loading was varied from $10-40 \mathrm{mg}$, the final $\mathrm{pH}$ of the reaction mixture was found to be 3.6 with $\mathrm{H}_{2} \mathrm{O}_{2}$ as the oxidant. The increase in the catalyst concentration to $80 \mathrm{mg}$ the $\mathrm{pH}$ of the solution changes to 4.8 . 
Turbidity in the reaction mixture is observed at this $\mathrm{pH}$ condition. With further increase in the catalyst loading to $150 \mathrm{mg}$, excess iron precipitates as iron oxy hydroxide which gets separated from the true solution and the $\mathrm{pH}$ of the solution changes to 5.6. But in the case of APS as the oxidant the final pH of the reaction medium was found to be 3.9 for all higher concentration of iron powder. Hence it can be concluded that APS effectively inhibits the precipitation of iron powder by providing excess acidity to the reaction medium.

\subsection{Effect of initial dye concentration}

Concentration of the substrate dye molecule affects the rate of degradation significantly in a photo Fenton process. Therefore experiments were performed at different initial dye concentrations by maintaining the other reaction parameters constant. The percentage degradation decreases to almost fifty percent for the $100 \mathrm{ppm}$ initial dye concentration. This may be due to the fact that, as the dye concentration increased, a proportional increase of hydroxyl radicals does not take place. High dye concentration prevents the UV light penetration into the depth of the solution, there by decreasing the extent of generation of hydroxyl radicals [21]. As reported by Reis et al. the active centers on the iron surface will be completely occupied by the dye molecules at high concentrations of the dye, which are capable of reducing the catalyst surface itself thereby hindering the process of generation of hydroxyl radicals [22]. The HMPFP shows higher efficiency compared to HAPFP at higher initial dye concentrations.

\subsection{Process efficiency $(\Phi)$}

The process efficiency $(\Phi)$ implies the effectiveness of the present method. It can be defined as the ratio of residual concentration of the pollutant to the amount of energy in terms of intensity and exposure surface area per time.

$\Phi=\frac{C_{0}-C}{t . I . S}$

where $C_{0}$ is the initial concentration of the dye substrate, $C$ is the concentration at time ' $t$ '. $\left(C_{0}-C\right)$ denotes the residual pollutant concentration in $\mathrm{mg} \mathrm{L}^{-1}$ or $\mathrm{ppm}$. ' $T$ ' is the irradiation intensity. ' $S$ ' denotes the solution irradiated plane surface area in $\mathrm{cm}^{2}$ and ' $t$ ' represents the irradiation time in minutes. Process efficiency under UV illumination is expressed in ppm Einstein ${ }^{-1}$. Process efficiency for the process in the absence of light is expressed as ppm. The results show that the HMPFP shows higher efficiency compared to all the other process (Table 1 ).

\subsection{Effect of inorganic salts (chloride and sulfate) on the degradation rate of ARS}

Presence of inorganic anions like chloride and sulfate ions in the waste water has a significant effect on the overall Fenton degradation reaction rate [23]. The presence of these anions in the reaction medium has decreased the degradation rate drastically. The first order rate constant $(k)$ value for HAPFP has decreased from $3.33 \times 10^{-2}$ to $0.28 \times 10^{-2} \mathrm{~min}^{-1}$ in presence of chloride ions and $0.13 \times 10^{-2} \mathrm{~min}^{-1}$ with sulfate ions. Similar decrease in $\mathrm{k}$ value for HMPFP process is from $4.672 \times 10^{-2}$ to $0.22 \times 10^{-2} \mathrm{~min}^{-1}$ in presence of chloride ions and $0.33 \times 10^{-2} \mathrm{~min}^{-1}$ with sulfate ions as shown in Fig. 1 (Table 1). In both HAPFP and HMPFP, the rate constant decreases drastically when sodium chloride is added. The addition of sodium chloride to an aqueous solution of ferric ions results in the formation of less reactive $\left[\mathrm{Fe}(\mathrm{Cl})^{2+}\right]$ and $\left[\mathrm{Fe}\left(\mathrm{Cl}_{2}\right)^{+}\right]$ complexes, although $\left[\mathrm{Fe}(\mathrm{OH})^{2+}\right]$ is still the predominant species at $\mathrm{pH}$ 3.0. In the absence of any added salt at $\mathrm{pH} 3.0$ the reaction is dominated by the photo reactive $\left[\mathrm{Fe}(\mathrm{OH})^{2+}\right]$ complex (Eq. (10)).

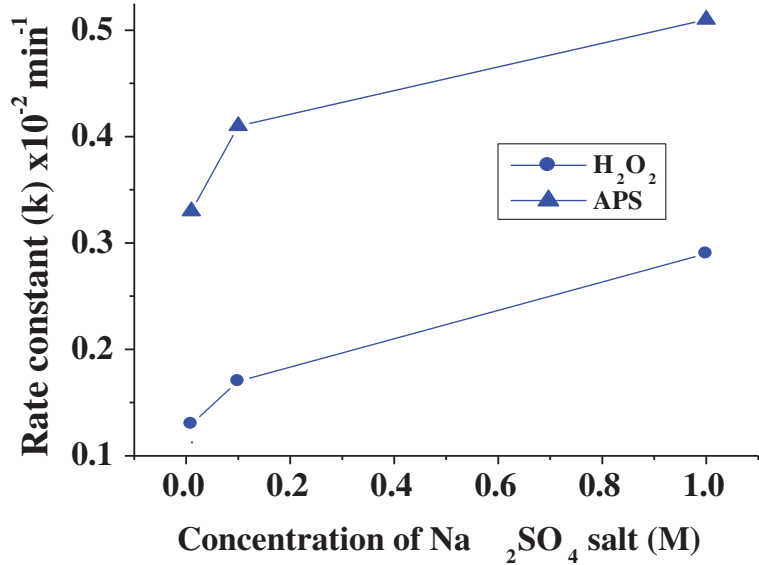

Fig. 2. Plot of rate constant versus concentration of $\mathrm{Na}_{2} \mathrm{SO}_{4}\left(\left[\mathrm{Fe}^{0}\right]=10 \mathrm{mg}\right.$, $[$ ARS $]=40 \mathrm{ppm},\left[\mathrm{H}_{2} \mathrm{O}_{2}\right]=20 \mathrm{ppm} /[$ APS $]=40 \mathrm{ppm}$ at $\mathrm{pH} 3.0 \pm 0.04$ ).

Further the generated ferrous ions reacts with hydrogen peroxide forming ferric ions and hydroxyl radicals as discussed previously (Eqs. (7) and (10)) [24,25]. The various possible reactions that can take place between chloride and $\mathrm{Fe}^{3+}$ ions are shown below:

$\mathrm{Fe}^{3+}+\mathrm{Cl}^{-} \leftrightarrow\left[\mathrm{Fe}(\mathrm{Cl})^{2+}\right]$

$\left[\mathrm{Fe}(\mathrm{Cl})^{2+}\right]+h v \rightarrow \mathrm{Fe}^{2+}+\mathrm{Cl}^{\bullet}$

$\mathrm{Cl}^{\bullet}+\mathrm{Cl}^{-} \rightarrow \mathrm{Cl}_{2}^{\cdot-}$

In presence of sodium sulfate, the degradation reaction rate constant decreases drastically for both HAPFP and HMPFP. Sulfate ions in aqueous solution can form complex with both ferrous and ferric ions of the type: $\mathrm{FeSO}_{4}, \mathrm{Fe}(\mathrm{OH})^{2+}$ and $\mathrm{FeSO}_{4}{ }^{+}$. This reduces the concentration of the ferrous and ferric ions in the solution whose concentration is most essential in Fenton Chemistry. At pH 3.0, $\mathrm{FeSO}_{4}{ }^{+}$and $\mathrm{Fe}(\mathrm{OH})^{2+}$ are the major predominant ferric species present. On irradiation with $\mathrm{UV}$ light $\mathrm{FeSO}_{4}{ }^{+}$produces ferrous ions and sulfate anions whose quantum yield is quite low $[23,24]$.

$\mathrm{FeSO}_{4}^{+}+h v \rightarrow \mathrm{Fe}^{2+}+\mathrm{SO}_{4}^{-}$

The influence of these anions on the degradation rate can be summed up as follows:

1) Both Fe (II) and Fe (III) ions form strong complexes with these anions, which effect the distribution and reactivity of the iron species present in the solution.

2) Both chloride and sulfate ions scavenge the hydroxyl radicals leading to the generation of the less reactive inorganic species like $\mathrm{Cl}^{-} \bullet$

3) Dichloride anion and sulfate radical anion are the major predominant contributors for the free radical degradation reaction mechanism in presence of chloride and sulfate ions.

The $\mathrm{Cl}_{2}{ }^{\bullet-}$ and $\mathrm{SO}_{4}{ }^{-}$are oxidant species formed and they are less reactive compared to the hydroxyl radicals [26,27].

4) In the presence of UV light the quinone group in the ARS molecule may interact more effectively with sulfate and chloride ions leading to a different degradation mechanisms.

\subsubsection{Effect of sulfate on degradation rate of ARS in HAPFP and HMPFP}

In case of HAPFP and HMPFP when the concentration of sodium sulfate is increased from 0.01 to $0.1 \mathrm{M}$, the rate constant increases slightly as shown in Fig. 2. The rate of degradation increases with further increase of sodium sulfate concentration to $1 \mathrm{M}$. The excess 




Fig. 3. Plot of rate constant versus concentration of $\mathrm{NaCl}\left(\left[\mathrm{Fe}^{0}\right]=10 \mathrm{mg}\right.$, $[\mathrm{ARS}]=40 \mathrm{ppm},\left[\mathrm{H}_{2} \mathrm{O}_{2}\right]=20 \mathrm{ppm} /[\mathrm{APS}]=40 \mathrm{ppm}$ at $\left.\mathrm{pH} 3.0 \pm 0.04\right)$.

sulfate ions react with water molecule leading to the generation of the hydroxyl radicals as shown below.

Other possible reactions at $\mathrm{pH} 3.0$ are:

$\mathrm{H}^{+}+\mathrm{SO}_{4}^{2-} \leftrightarrow \mathrm{HSO}_{4}^{-}$

$\mathrm{HSO}_{4}{ }^{-}+\mathrm{OH}^{\bullet} \rightarrow \mathrm{SO}_{4}{ }^{-}+\mathrm{H}_{2} \mathrm{O}$

$\mathrm{SO}_{4}{ }^{--}+\mathrm{H}_{2} \mathrm{O} \rightarrow \mathrm{H}^{+}+\mathrm{SO}_{4}{ }^{2-}+\mathrm{OH}^{\bullet}$

$\mathrm{SO}_{4}{ }^{-}+\mathrm{H}_{2} \mathrm{O}_{2} \rightarrow \mathrm{H}^{+}+\mathrm{SO}_{4}{ }^{2-}+\mathrm{OH}_{2}{ }^{\bullet}$

$\mathrm{SO}_{4}{ }^{-}+2 \mathrm{OH}_{2}{ }^{\bullet} \rightarrow 4 \mathrm{H}^{+}+\mathrm{SO}_{4}{ }^{-}+\mathrm{O}_{2}$

$\mathrm{SO}_{4}{ }^{-}+\mathrm{SO}_{4}{ }^{-}-\mathrm{S}_{2} \mathrm{O}_{8}{ }^{2-}$

$\mathrm{Fe}^{2+}+\mathrm{SO}_{4}{ }^{-} \rightarrow \mathrm{Fe}^{3+}+\mathrm{SO}_{4}{ }^{2-}$

$\mathrm{SO}_{4}{ }^{2-}+\mathrm{Cl}^{\bullet} \rightarrow \mathrm{SO}_{4}{ }^{-}+\mathrm{Cl}^{-}$

The rate of degradation in HMPFP is high compared to HAPFP, due to the higher concentration of the hydroxyl radicals generated in this process.

\subsubsection{Effect of chloride ions}

In HAPFP, the rate constant decreases slightly when sodium chloride is added. In case of HMPFP process when the concentration of sodium chloride is increased from 0.01 to $1 \mathrm{M}$ rate constant increases slightly as shown in Fig. 3.

Some of the sulfate radical anions (from APS) react with water molecule to generate hydroxyl radicals (Eq. (27)). Sulfate ion can react with chloride radical leading to the formation of sulfate anion radical (Eq. (32)) which later yields hydroxyl radicals. Sulfate ions can also react with chloride radical to form hydroxyl radical. Therefore the concentrations of hydroxyl radicals are sustained to some extent. In case of HAPFP the rate of degradation decreases slightly when concentration of sodium chloride is increased from 0.01 to $1 \mathrm{M}$ (Fig. 3). When the chloride ion concentration increases in the photo assisted Fenton reactions at $\mathrm{pH} 3$ in situ formation of the $\mathrm{FeCl}^{2+}$ complex takes place and this complex competes with the Fe $(\mathrm{OH})^{2+}$ complex for UV light photons and hence the rate of production of hydroxyl radical decreases. $\mathrm{Cl}^{-}$acts as a strong free radical scavenger and it reacts with $\mathrm{OH}^{\bullet}$ under acidic $\mathrm{pH}$ conditions [28-30].

$\mathrm{Cl}^{-}+\mathrm{OH}^{\bullet} \rightarrow \mathrm{ClOH}^{\bullet}$

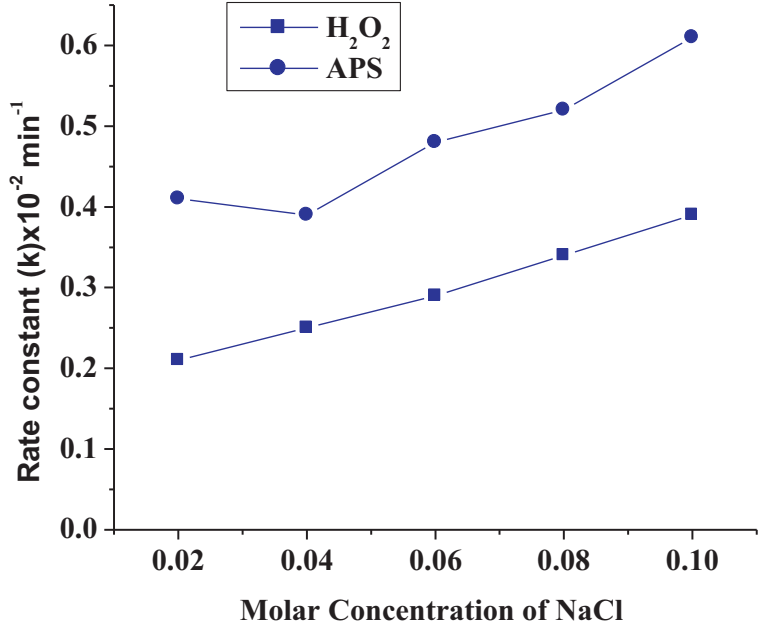

Fig. 4. Plot of rate constant versus concentration of $\mathrm{NaCl}$. $\left(\left[\mathrm{Fe}^{0}\right]=10 \mathrm{mg}\right.$, $[\mathrm{ARS}]=40 \mathrm{ppm}, \quad\left[\mathrm{H}_{2} \mathrm{O}_{2}\right]=20 \mathrm{ppm} /[\mathrm{APS}]=40 \mathrm{ppm}$ and $\left[\mathrm{Na}_{2} \mathrm{SO}_{4}\right]=1 \mathrm{M}$ at $\mathrm{pH}$ $3.0 \pm 0.04)$.

$\mathrm{ClOH}^{-}+\mathrm{Fe}^{2+} \rightarrow \mathrm{Cl}^{-}+\mathrm{OH}^{-}+\mathrm{Fe}^{3+}$

In presence of chloride ions various inorganic radicals like $\mathrm{Cl}^{\bullet}$, $\mathrm{HClOH}^{\bullet}, \mathrm{ClOH}^{\bullet-}, \mathrm{Cl}_{2}{ }^{\bullet-}$ are formed among which, the dichloride anion radical is predominant and hence a greater trend in the decrease of the degradation rate is observed and it inhibits the production of hydroxyl radicals [31,32].

\subsection{Combined effect of chloride and sulfate ions}

Combined effect of concentration of chloride and sulfate ions on the degradation of ARS using hydrogen peroxide and APS as the oxidants was studied. The concentration of sodium sulfate (1 M) is kept constant and concentration of sodium chloride is varied from 0.02 to $0.10 \mathrm{M}$ for both HAPFP and HMPFP as shown in the Fig. 4.

In the case of HAPFP the rate constant increases from $0.2 \times 10^{-2}$ to $0.39 \times 10^{-2}$ when the concentration of $\mathrm{NaCl}$ was varied from 0.02 to $0.1 \mathrm{M}$. Similar increase in the rate constant from $0.41 \times 10^{-2}$ to $0.61 \times 10^{-2}$ was observed for HMPFP.

The maximum retardation of the rate is observed in case of HAPFP compared to HMPFP. The maximum quenching of hydroxyl free radicals by chloride free radicals takes place in the case of HAPFP, where hydrogen peroxide is used as the oxidant. In presence of UV light more number of chloride free radicals are produced as the concentration of sodium chloride is increased. These free radicals react with sulfate ions leading to the formation of sulfate anion radical (Eq. (32)) which further generates hydroxyl radicals according to Eq. (27).

In the other experiment the concentration of sodium chloride $(1 \mathrm{M})$ is kept constant and concentration of sodium sulfate is varied from 0.02 to $0.10 \mathrm{M}$ for both HAPFP and HMPFP. The results are shown in the Fig. 5.

In both the cases the degradation rate increases gradually with increase in concentration of sodium sulfate. The degradation rate is slightly high in HMPFP compared to HAPFP. The concentration of sulfate anions are more in case of HMPFP compared to HAPFP.

The sulfate anion radical further participates in the degradation reaction mechanism as shown in the (Eqs. (25)-(32)). Hydroxyl and hydroperoxyl radicals are further generated. The extent of production of these radicals and the rate at which they are produced will dictate the degradation reaction rate. However one can conclude that the observed rate constants in the presence of sulfate and chloride ions are very low compared to the degradation reaction in the absence of these ions. 


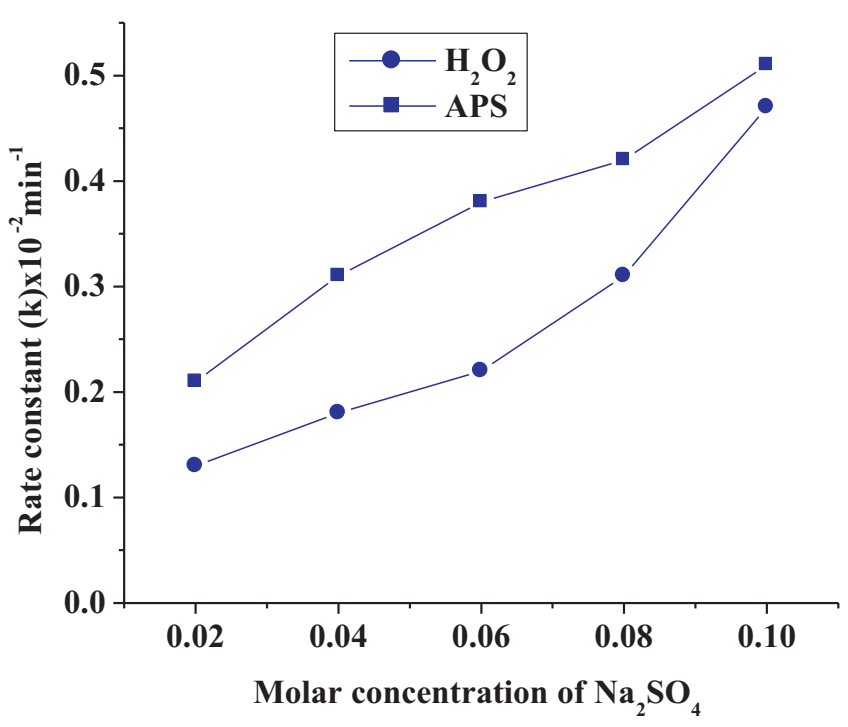

Fig. 5. Plot of rate constant versus concentration of $\mathrm{Na}_{2} \mathrm{SO}_{4}$. $\left(\left[\mathrm{Fe}^{0}\right]=10 \mathrm{mg}\right.$, $[$ ARS $]=40 \mathrm{ppm},\left[\mathrm{H}_{2} \mathrm{O}_{2}\right]=20 \mathrm{ppm} /[\mathrm{APS}]=40 \mathrm{ppm}$ and $[\mathrm{NaCl}]=1 \mathrm{M}$ at $\left.\mathrm{pH} 3.0 \pm 0.04\right)$.

\subsection{UV-visible and GC-MS analysis}

The $\lambda_{\max }$ of the ARS at $\mathrm{pH} 3$ is found to be $422 \mathrm{~nm}$ before the initiation of the reaction. In the absence of inorganic salts, there was continuous decrease in the absorbance of this peak in the photo Fenton process. However, in the presence of inorganic salt, the peak corresponding to the $\lambda_{\max }$ showed red shift to $525-536 \mathrm{~nm}$. This shift was observed over the entire concentration range of $\mathrm{NaCl} / \mathrm{Na}_{2} \mathrm{SO}_{4}$ and the intensity of absorbance increased with increase in the concentration. The GC-MS analysis has been performed for the experiment $\mathrm{Fe}^{0} / \mathrm{APS} / \mathrm{UV}$ (HMPFP) ( $[$ ARS $]=40 \mathrm{ppm},\left[\mathrm{Fe}^{0}\right]=10 \mathrm{mg}$ and $[\mathrm{APS}]=40 \mathrm{ppm}$ at $\mathrm{pH} 3.0 \pm 0.04$ exposed to UV irradiation) which shows higher efficiency. During the degradation process about $4 \mathrm{ml}$ of the sample was withdrawn at regular time intervals and this solution was centrifuged and filtered to remove the catalyst particles present in the solution. The samples were further extracted into a non aqueous ether medium and $1.0 \mu \mathrm{l}$ of each of this solution is injected into the GC-MS instrument. The various major reaction intermediates formed during the process of degradation were analyzed by GC-MS technique and the results are presented in Table 2 . Several low intensity $\mathrm{m} / \mathrm{z}$ peaks corresponding to the minor intermediate products were left unidentified. A probable degradation reaction mechanism has been proposed based on the UV-visible and GC-MS spectroscopic analysis is shown in Fig. 6.

Table 2

List of the major intermediate products identified by GC-MS technique at various time intervals during the degradation of ARS.

\begin{tabular}{ccl}
\hline Irradiation time $(\mathrm{min})$ & $m / z$ values & Intermediate products \\
\hline 30 & 165 & Pthalic acid (1) \\
138 & Salicylic acid (2) \\
& 174 & o-Hydroxy sulfonic acid (3) \\
& 110 & Catechol (1, 2 dihydroxybenzene) (4) \\
60 & 108 & Cyclo 3, 5- hexadiene 1, 2-dienone (5) \\
& 96 & Sulfate anion \\
90 & 44 & Carbon dioxide \\
& 18 & Water molecules
\end{tabular}

The number in the parenthesis represents the intermediate products in the proposed mechanism (Fig. 6).

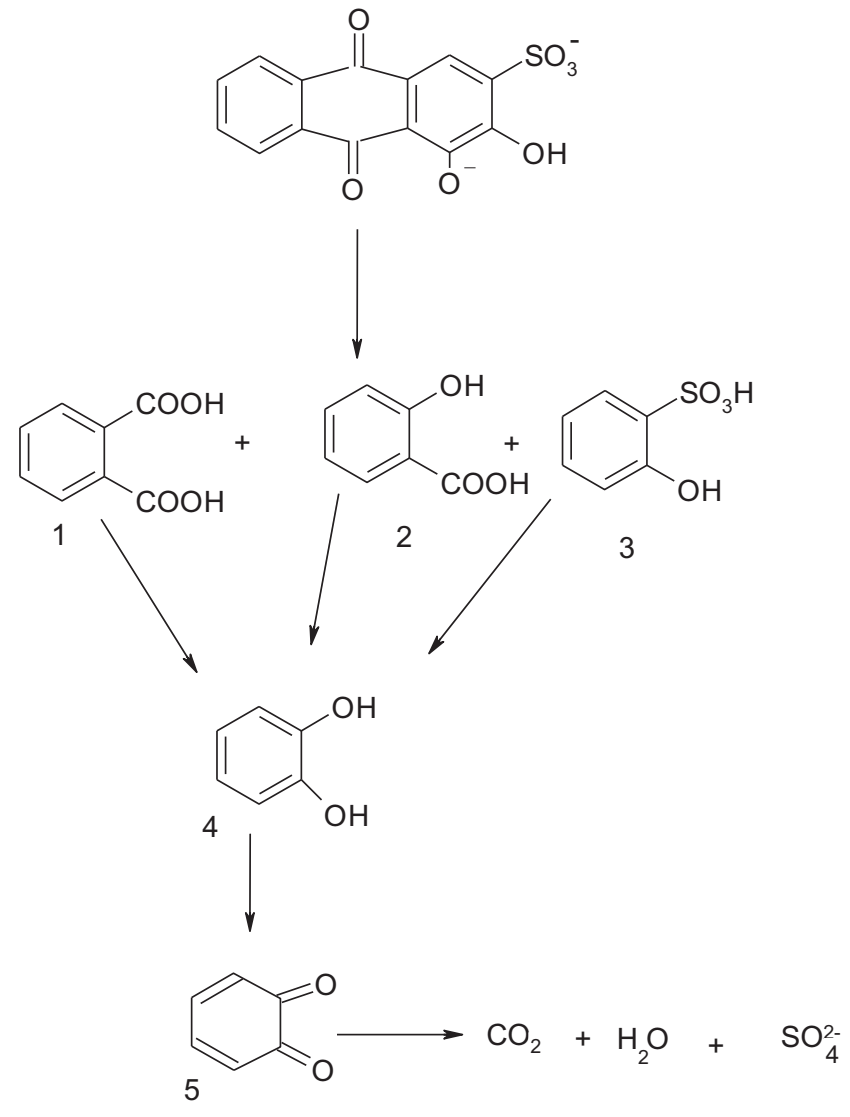

Fig. 6. Probable degradation reaction mechanism pathway of ARS.

\section{Conclusion}

The influence of various inorganic anions that are commonly found in industrial effluents on the degradation mechanism is studied. Both sulfate and chloride ions retard the efficiency of the process by scavenging the hydroxyl radical and also by forming the complexes with iron ions. These inorganic ions reduce the rate of generation of hydroxyl radicals from Fenton reagents. The maximum retardation of the rate is observed in case of HAPFP compared to HMPFP. However the degradation process was not completely quenched since some of the less reactive radicals like $\mathrm{Cl}^{\bullet}, \mathrm{HClOH}^{\bullet}$, $\mathrm{ClOH}^{\bullet}, \mathrm{Cl}_{2}{ }^{\bullet-}, \mathrm{SO}_{4}{ }^{\bullet-}, \mathrm{OH}_{2} \bullet$ are formed and the degradation reaction is sustained. The extent of formation of higher reactive ions among these ions will decide the fate of the reaction. However one could conclude that the most reactive radical is hydroxyl free radical, higher reaction rate in the absence of salts confirms this fact.

\section{Acknowledgements}

Financial support from DST-SERC major research project, DSTIDP major research project and UGC major research project is acknowledged.

\section{References}

[1] A. Rathi, H.K. Rajor, R.K. Sharma, J. Hazard. Mater. 102 (2003) 231-241.

[2] M.Y. Ghaly, G. Hartel, R. Mayer, R. Haseneder, Waste Manage. 21 (2001) 41-47.

[3] S. Kim, W. Choi, Environ. Sci. Technol. 36 (2002) 2019-2027.

[4] Y. Sun, J.J. Pignatello, Environ. Sci. Technol. 27 (1993) 304-310.

[5] I. Muthuvel, M. Swaminathan, Catal. Commun. 8 (2007) 981-986.

[6] J. Yu, X. Yu, B. Huang, X. Zhang, Y. Dai, Cryst. Growth Des. 9 (3) (2009) $1474-1480$.

[7] X. Zhou, J. Lan, G. Liu, K. Deng, Y. Yang, G. Nie, J. Yu, L. Zhi, Angew. Chem. Int. Ed. 51 (2012) 178-182. 
[8] Q. Xiang, J. Yu, P.K. Wong, J. Colloid. Interface Sci. 357 (2011) 163-167.

[9] J. Zhou, Z. Zhang, B. Cheng, J. Yu, Chem. Eng. J. 211-212 (15) (2012) 153-160.

[10] F. Lucking, H. Koser, M. Jank, A. Ritter, Water. Res. 32 (1998) 2607-2614.

[11] L. Gomathi Devi, G.M. Krishnaiah, J. Photochem. Photobiol.: Chem. 121 (1999) $141-145$.

[12] J. Lee, H.H. Seliger, J. Chem. Phys. 40 (1964) 519-523.

[13] S.F. Kang, C.H. Liao, M.C. Chen, Chemosphere 46 (2002) 923-928.

[14] C.F. Baes, R.E. Mesmer, The Hydrolysis of Cations, John-Wiley and sons, New York, 1976.

[15] M. Neamtu, A. Yediler, I. Siminiceanu, A. Kettrup, J. Photochem. Photobiol. A 161 (2003) 87-93.

[16] K. Barbusinski, J. Majewski, Pol. J. Environ. Stud. 12 (2003) 151-155.

[17] H.E. Feng, Le-cheng, Lei, New. J. Chem. 5 (2004) 198-205.

[18] P. Neta, V. Madhavan, H. Zemel, R.W. Fessemdem, J. Am. Chem. Soc. 99 (1977) $163-164$.

[19] L. Gomathi Devi, S. Girish Kumar, K. Mohan Reddy, C. Munikrishnappa, J. Hazard. Mater. 164 (2009) 459-467.
[20] O.S.N. Sum, J.Y. Feng, X.J. Hu, P.L. Yue, Top. Catal. 33 (2005) 233-242.

[21] K. Dutta, S. Mukhopadhyay, S. Bhattacharjee, B. Chaudhuri, J. Hazard. Mater. 84 (2001) 57-71.

[22] F.A.P. Reis, E.M. Azeved, J.C.R. Nozaki, Sol. Energy 77 (2004) 29-35.

[23] D.L. Joseph, T. Le Giang, L. Bernard, Chemosphere 55 (2004) 715-723.

[24] Amilcar Machulek Jr., J.E. Moraes, L.T. Okano, C.A. Silvério, F.H. Quina, Photochem. Photobiol. Sci. 8 (2009) 985-991.

[25] J. Kiwi, A. Lopez, V. Nadtochenko, Environ. Sci. Technol. 34 (2000) 2162-2168.

[26] P. Neta, R.E. Huie, A.B. Ross, J. Phys. Chem. 17 (1988) 1027-1247.

[27] Y. Dong, J. Chen, C. Li, H. Zu, Dyes Pigm. 73 (2007) 261-268.

[28] C. Chiing-Chang, W. Ren-Jang, T. Yi-You, L. Chung-Shin, J. Chin. Chem. Soc. Taip. 56 (2009) 1147-1155.

[29] H. Chen, T. Zhang, J. Zhang, J. Hazard. Mater. 161 (2009) 1473-1477.

[30] S.S. Ashraf, A.M. Rauf, S. Alhadrami, Dyes Pigm. 69 (2006) 74-78.

[31] Q. Yinan, C. Shang, M.C. Lo Irene, Water. Res. 38 (2004) 2375-2383.

[32] E.M. Siedlecka, P. Stepnowski, Pol. J. Environ. Stud 14 (2005) 823-828. 